\title{
Prognostic Value of Serum Creatinine Levels in Patients with Epithelial Ovarian Cancer
}

\author{
JUDITH LAFLEUR ${ }^{1,2}$, KATRIN HEFLER-FRISCHMUTH $^{3}$, CHRISTOPH GRIMM $^{4}$, \\ RICHARD SCHWAMEIS $^{1,4}$, LISA GENSTHALER ${ }^{4}$, ELISABETH REISER ${ }^{4}$ and LUKAS A. HEFLER ${ }^{1,2}$ \\ Departments of ${ }^{1}$ Gynecology, and ${ }^{3}$ Internal Medicine I, Ordensklinikum Linz, Linz, Austria; \\ ${ }^{2}$ Karl Landsteiner Institute of Gynecologic Surgery and Oncology, Linz, Austria; \\ ${ }^{4}$ Department of General Gynecology and Gynecologic Oncology, Gynecologic Cancer Unit, \\ Comprehensive Cancer Center, Medical University of Vienna, Vienna, Austria
}

\begin{abstract}
Aim: To evaluate preoperative serum creatinine level as a prognostic parameter in patients with primary epithelial ovarian cancer (EOC). Patients and Methods: In a retrospective cohort study, serum levels of creatinine were evaluated in 498 patients with EOC. Data were extracted from our prospectively maintained database. Results were correlated with clinicopathological parameters and patient survival. Results: The mean pre-therapeutic serum creatinine level in patients with EOC was $0.84 \pm 0.40 \mathrm{mg} / \mathrm{dI}$. A serum creatinine level of $1.2 \mathrm{mg} / \mathrm{dl}$ or higher was found in 22 (4.4\%) patients and associated with poor survival. In a multivariate logistic regression analysis, the serum creatinine level was a significant independent prognostic parameter of overall survival. Conclusion: The preoperative serum level of creatinine may be useful as an additional independent prognostic parameter in patients with EOC.
\end{abstract}

Recently, a published study reported preoperative hyponatremia, elevated serum creatinine level, hypoalbuminemia, and thrombocytosis to be associated with perioperative morbidity in patients with epithelial ovarian cancer (EOC) (1). Various studies have also shown a significant prognostic influence of serum albumin level (2) and thrombocyte counts (3), while as far as we are aware of, no data are available on patients with EOC regarding elevated serum creatinine level.

Impaired renal function at diagnosis of a malignant disease has been linked to increased postoperative morbidity and worsened survival (4). Serum creatinine has been investigated as a prognostic parameter in colorectal (5), upper urinary

Correspondence to: Lukas A. Hefler, MD, Department of Gynecology, Ordensklinikum Linz, Austria, Seilerstätte 4, A-4020 Linz, Austria. Tel: +43 73276777160, Fax: +43 73276777168, e-mail: lukas.hefler@ordensklinikum.at

Key Words: Ovarian cancer, creatinine, prognosis. tract/urothelial (6), and prostate (7) cancer, as well as liposarcoma (4) and multiple myeloma (8). It can be hypothesized that an elevated serum creatinine level is indicative of impaired kidney function, reflecting frailty or a poor performance status. These conditions can lead to greater reluctance of treating physicians to plan major surgery, to reduced tolerability of an individual patient of cytoreductive surgery, and a higher probability of discontinuation or the necessity for a reduced dose of chemotherapy. An elevated serum creatinine level can therefore be seen only as surrogate marker for a patient's reduced physical status. Whether or not the serum creatinine level influences a patient's course of disease has not been resolved.

The aim of the present study was to investigate whether an elevated serum creatinine level can serve as an additional, cheap, and readily available prognostic parameter reflecting overall survival in patients with EOC.

\section{Patients and Methods}

Patients. A total of 498 patients with EOC were included in the present retrospective cohort study. All patients were treated between 2000 and 2015 at the Department of General Gynecology and Gynecologic Oncology, Medical University of Vienna, Austria. The Institutional Review Board of the Medical University of Vienna approved the present study (IRB approval number: 247/2009). Individual patient data were extracted from our database. At the time of EOC diagnosis, a physical examination was performed as were routine blood tests, including the serum level of creatinine. Patients were treated according to local standards with cytoreductive surgery and adjuvant platinum-based chemotherapy with/without bevacizumab. Surgical staging was performed according to International Federation of Gynecologists and Obstetricians (FIGO) guidelines (9), including hysterectomy, bilateral salpingooophorectomy, pelvic/para-aortic lymphadenectomy, appendectomy, omentectomy and additional cytoreductive procedures to resect all gross tumor. All patients with FIGO tumor stages IC to IV and all patients with clear-cell carcinoma received an adjuvant platinumbased chemotherapy. Post-therapeutically, all patients were followed-up four times annually, including pelvic examination, 
abdominal ultrasound examination, and serum evaluation of cancer antigen 125 (CA-125) for the first 3 years, afterwards twice yearly for 2 years, and thereafter once annually for further 5 years.

As part of our Institutional clinical routine, blood samples were obtained by peripheral venous puncture 24 to $72 \mathrm{~h}$ prior to surgery. Serum creatinine was measured using the Creatinine Jaffé Gen. 2 test (COBAS CREJ2; Roche Diagnostics, Indianapolis, IN, USA). Serum creatinine concentrations between $0.50-1.2 \mathrm{mg} / \mathrm{dl}$ were considered normal.

Statistical analysis. Values are given as the means with standard deviation (SD). Variables were compared using the Pearson's correlation coefficient, $t$-test, and one-way ANOVA, where appropriate. Survival probabilities were calculated by the productlimit method of Kaplan and Meier. Differences between groups were tested using the log-rank test. Univariate and multivariate Cox regression models for overall survival were performed including tumor stage (FIGO I $v s$. II $v s$. III $v s$. IV), presence of postoperative residual tumor mass (present $v s$. absent), histological grade (G1 vs. G2 vs. G3), histological type (serous vs. all other), age, and serum creatinine level. The results were analyzed for the endpoint of overall survival. Only cancer-related death was regarded as an event, patients who died due to other reasons or were alive even with tumor present at the time of last follow-up were censored at the date of last follow-up. Survival times of disease-free patients or those still alive, or dead as a result of other causes, were censored at the last follow-up date. A multivariate model was used with all established clinical prognostic parameters and serum creatinine as a dichotomous variable $(<v s . \geq 1.2 \mathrm{mg} / \mathrm{dl})$. The value of $1.2 \mathrm{mg} / \mathrm{dl}$ was used as a cut-off since serum creatinine levels over $1.2 \mathrm{mg} / \mathrm{dl}$ are defined as being pathological. $p$-Values of less than 0.05 were considered statistically significant. Hazard ratios (HR) and 95\% confidence intervals $(\mathrm{CI})$ are provided. For statistical analysis, the Statistical Package for the Social Sciences statistical software was used (SPSS 22.0 IBMCorp., Armonk, NY, USA).

\section{Results}

Patient characteristics are shown in Table I. Overall, the mean pre-therapeutic serum creatinine level in patients with EOC was $0.84 \pm 0.4 \mathrm{mg} / \mathrm{dl}$. Serum creatinine $(\geq 1.2 \mathrm{mg} / \mathrm{dl})$ was elevated in $22(4.4 \%)$ patients. The association between investigated serum parameters and clinicopathological parameters are shown in Table II. Elevated serum creatinine levels were associated only with patient age $(\mathrm{r}=0.2, p<0.001)$.

In the univariate analysis, serum creatinine was considered both as a continuous variable and separately as a dichotomous variable using the cut-off of $1.2 \mathrm{mg} / \mathrm{dl}$. Serum creatinine reached statistical significance as both continuous and dichotomous variable, as did all establish clinical prognostic parameters (Table III). Figure 1 shows the overall survival of patients dependent on serum creatinine level using a cut-off of $1.2 \mathrm{mg} / \mathrm{dI}$. In the multivariate analysis, serum creatinine remained significantly and independently negatively associated with overall survival as both a continuous and dichotomous variable. A higher serum creatinine level was predictive of a significantly impaired prognosis.
Table I. Study patient characteristics.

\begin{tabular}{lc}
\hline Parameter & Value \\
\hline Number of patients & 498 \\
Age at first diagnosis, mean \pm SD, years & $58.7 \pm 14.7$ \\
Length of follow-up, mean \pm SD, months & $37.0 \pm 32.8$ \\
Recurrence status & \\
Patients with recurrent disease, n (\%) & $299(60.0 \%)$ \\
Time to recurrent disease, mean \pm SD, months & $14.9 \pm 12.6$ \\
Status at last observation, n $(\%)$ & $179(35.9 \%)$ \\
Alive with no evidence of disease & $33(6.6 \%) / 69(13.9 \%)$ \\
Stable disease/progressive disease & $196(39.4 \%)$ \\
Dead as a result of disease & $21(4.2 \%)$ \\
Dead as a result of other causes & \\
\hline
\end{tabular}

SD: Standard deviation.

Table II. Patient characteristics and correlation with the evaluated parameters of the study group.

\begin{tabular}{lccc}
\hline Parameter & & $\begin{array}{c}\text { Serum creatinine } \\
(\mathrm{mg} / \mathrm{dI})\end{array}$ & $p$-Value \\
& & - & - \\
\hline $\begin{array}{l}\text { Total patients } \\
\text { Age at first diagnosis, }\end{array}$ & 498 & & $<0.001^{\ddagger}$ \\
mean \pm SD, years & $58.7 \pm 14.7$ & & \\
FIGO tumor stage & & & $0.08^{*}$ \\
I & 92 & $0.9 \pm 0.4$ & \\
II & 35 & $0.8 \pm 0.2$ & \\
III & 296 & $0.9 \pm 0.8$ & \\
IV & 75 & & \\
Postoperative residual & & & \\
tumor mass & & $0.8 \pm 0.5$ & \\
Present & 152 & $0.8 \pm 0.2$ & \\
Absent & 247 & $0.9 \pm 0.2$ & \\
Unknown & 99 & $0.8 \pm 0.2$ & $0.5^{*}$ \\
Histological grade & & $0.9 \pm 0.4$ & \\
G1 & 76 & $0.8 \pm 0.4$ & \\
G2 & 117 & & \\
G3 & 305 & $0.8 \pm 0.4$ & $0.9^{\dagger}$ \\
Histological type & & $0.8 \pm 0.3$ & \\
$\quad$ Serous & 328 & & \\
Non serous & 170 & & \\
\hline
\end{tabular}

FIGO: International Federation of Gynecologists and Obstetricians, SD: standard deviation. *One-way ANOVA, ${ }^{*} t$-test, ${ }^{*}$ Pearson’s correlation coefficient.

\section{Discussion}

In the present study, a high serum creatinine level was associated with impaired overall survival in patients with EOC. A number of laboratory parameters have been shown to be associated with impaired prognosis in patients with EOC including markers of inflammation, serum tumor markers, thrombocytosis, serum level of angiotensinconverting enzyme and cell-surface markers expressed by the 
Table III. Univariate and multivariate overall survival analysis in 498 patients with epithelial ovarian cancer.

\begin{tabular}{|c|c|c|c|c|c|}
\hline \multirow[t]{2}{*}{ Factor } & \multirow[b]{2}{*}{ Comparison } & \multirow{2}{*}{$\begin{array}{c}\text { Univariate } \\
p \text {-value }\end{array}$} & \multicolumn{3}{|c|}{ Multivariate } \\
\hline & & & Hazard ratio & $95 \% \mathrm{CI}$ & $p$-Value \\
\hline FIGO tumor stage & I $v s$. II $v s$. III $v s$. IV & $<0.001 *$ & 1.7 & $1.2-2.2$ & 0.001 \\
\hline Postoperative residual tumor mass & absent $v s$. present & $<0.001 *$ & 2.3 & $1.5-3.6$ & $<0.001$ \\
\hline Histological grade & $\mathrm{G} 1$ vs. G2 vs. G3 & $<0.001 *$ & 1.2 & $0.9-1.7$ & 0.2 \\
\hline Histological type & Serous vs. other & $0.005^{*}$ & 1.0 & $0.6-1.7$ & 0.9 \\
\hline Patient age & $\geq v s .<60$ Years & $<0.001^{\dagger}$ & 1.05 & $1.03-1.07$ & $<0.001$ \\
\hline Serum creatinine & $\geq v s .<1.2 \mathrm{mg} / \mathrm{dl}$ & $<0.001 *$ & 2.2 & $1.1-4.7$ & 0.03 \\
\hline
\end{tabular}

FIGO: International Federation of Gynecologists and Obstetricians; CI: confidence interval. ${ }^{*}$ Log-rank test; ${ }^{\dagger}$ univariate Cox-regression analysis.

tumor cells (10-14). Interestingly, recently published studies investigated whether medical interventions such as antihypertensive medication or parenteral nutrition influence the prognosis of patients with cancer by altering circulating inflammatory markers or serum albumin levels $(15,16)$. Our study is in line with the aforementioned data, as the independent prognostic factor ascertained in our study, namely the serum level of creatinine, can be changed by medical interventions. Therefore, this could serve as a potential target in future clinical trials aimed to normalize the preoperative level of creatinine in order to beneficially affect patient prognosis.

Comparable to assessing red blood cell counts, investigating preoperative renal function seems valuable in planning surgery and estimating the patient's risk of postoperative complications. To date, guidelines acknowledge treating that tumor-associated anemia can reduce complications and possibly improve overall survival $(17,18)$. Based on previously published data and on the results of the present study, it can be hypothesized that it may be clinically useful to assess renal function at the time of EOC diagnosis and eventually improve renal function in the preoperative setting. In the present study, serum creatinine was prognostically relevant when used as a continuous variable, with a cut-off value of $1.2 \mathrm{mg} / \mathrm{dl}$. Thus, we encourage others to use this cut-off value when using serum creatinine as a tool for preoperative optimization of patients with EOC.

Due to the availability of new targeted therapies and its implication for family members, recommendations for genetic testing regarding breast cancer 1 and 2 genes $(B R C A 1 / 2)$ were issued recently (19). Due to the retrospective design of our study, we included patients that were diagnosed with EOC between 2000 and 2015. Therefore, data regarding $B R C A$ mutation was lacking in many of the cases. Another interesting hypothesis, which has to be kept in mind when interpreting the results of our study, is the fact that a high serum creatinine level is associated

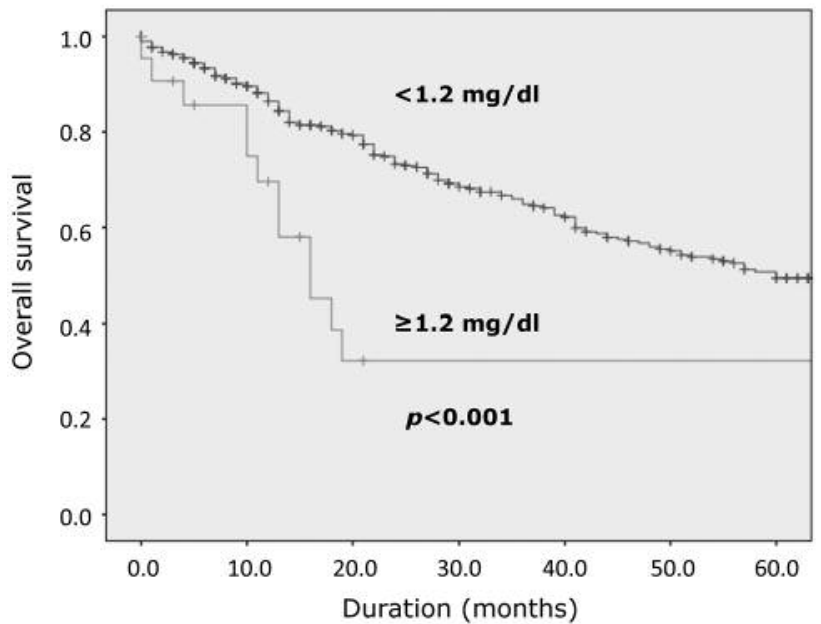

Figure 1. Kaplan-Meier analysis of overall survival of patients with ovarian cancer dependent on serum creatinine level using a cut-off of $1.2 \mathrm{mg} / \mathrm{dI}$

with renal impairment in general. As patients included in the present study were treated with chemotherapy, it can be hypothesized that the observed worse prognosis might be due to the malignancy of the cancer itself or due to the intolerance to chemotherapy that might lead to renal failure. As we have no data available regarding side-effects of chemotherapy regimens, we cannot support one or the other assumption.

In summary, our study showed that the serum level of creatinine is an independent prognostic parameter of overall survival among patients with primary EOC. Our data support the need for preoperative assessment of creatinine. This is of particular interest as this factor could be corrected preoperatively. The prognostic value of preoperative correction of high creatinine level should be tested in further clinical studies. 


\section{Conflicts of Interest}

None of the Authors have any actual or potential conflict of interest including any financial, personal or other relationships with other people or organizations that could inappropriately influence, or be perceived to influence, their work to disclose.

\section{References}

1 Martin JY, Goff BA and Urban RR: Preoperative hyponatremia in women with ovarian cancer: An additional cause for concern? Gynecol Oncol 142: 471-476, 2016.

2 Ataseven B, du Bois A, Reinthaller A, Traut A, Heitz F, Aust S, Prader S, Polterauer S, Harter P and Grimm C: Pre-operative serum albumin is associated with post-operative complication rate and overall survival in patients with epithelial ovarian cancer undergoing cytoreductive surgery. Gynecol Oncol 138: $560-565,2015$.

3 Cozzi GD, Samuel JM, Fromal JT, Keene S, Crispens MA, Khabele D and Beeghly-Fadiel A: Thresholds and timing of preoperative thrombocytosis and ovarian cancer survival: Analysisof laboratory measures from electronic medical records. BMC Cancer 16: 612, 2016.

4 Panotopoulos J, Posch F, Funovics PT, Willegger M, Scharrer A, Lamm W, Brodowicz T, Windhager R and Ay C: Elevated serum creatinine and low albumin are associated with poor outcomes in patients with liposarcoma. J Orthop Res 34: 533-538, 2016.

5 Giessen-Jung C, Nagel D, Glas M, Spelsberg F, Lau-Werner U, Modest DP, Schulz C, Heinemann V, Di Gioia D and Stieber P: Preoperative serum markers for individual patient prognosis in stage I-III colon cancer. Tumour Biol 36: 7897-7906, 2015.

$6 \mathrm{Kim}$ M, Moon KC, Choi WS, Jeong CW, Kwak C, Kim HH and $\mathrm{Ku} \mathrm{JH}$ : Prognostic value of systemic inflammatory responses in patients with upper urinary tract urothelial carcinoma. World $\mathrm{J}$ Urol 33: 1439-1457, 2015.

7 Tollefson MK, Boorjian SA, Gettman MT, Rangel LJ, Bergstralh EJ and Karnes RJ: Preoperative estimated glomerular filtration rate predicts overall mortality in patients undergoing radical prostatectomy. Urol Oncol 31: 1483-1488, 2013.

8 Chen JH, Hsu SN, Huang TC, Wu YY, Lin C, Chang PY, Chen YC and Ho CL: Prognostic significance of initial serum albumin and 24-hour daily protein excretion before treatment in multiple myeloma. PloS One 10: e0128905, 2015.

9 Prat J, for the FIGO Committee on Gynecologic Oncology: Staging classification for cancer of the ovary, fallopian tube, and peritoneum. Int J Gynaecol Obstet 124: 1-5, 2014.

10 Beyazit F, Ayhan S, Celik HT and Gungor T: Assessment of serum angiotensin-converting enzyme in patients with epithelial ovarian cancer. Arch Gynecol Obstet 292: 415-420, 2015.
11 Huo J, Hu J, Liu G, Cui Y and Ju Y: Elevated serum interleukin37 level is a predictive biomarker of poor prognosis in epithelial ovarian cancer patients. Arch Gynecol Obstet 295: 459-465, 2017.

12 Luo Y, Kim HS, Kim M, Lee M and Song YS: Elevated plasma fibrinogen levels and prognosis of epithelial ovarian cancer: A cohort study and meta-analysis. J Gynecol Oncol 28: e36, 2017.

13 Menczer J: Preoperative elevated platelet count and thrombocytosis in gynecologic malignancies. Arch Gynecol Obstet 295: 9-15, 2017.

14 Zwakman N, van de Laar R, Van Gorp T, Zusterzeel PL, Snijders MP, Ferreira I, Massuger LF and Kruitwagen RF: Perioperative changes in serum CA125 levels: A prognostic factor for disease-specific survival in patients with ovarian cancer. J Gynecol Oncol 28: e7, 2017.

15 Coulson R, Liew SH, Connelly AA, Yee NS, Deb S, Kumar B, Vargas AC, O'Toole SA, Parslow AC, Poh A, Putoczki T, Morrow RJ, Alorro M, Lazarus KA, Yeap EFW, Walton KL, Harrison CA, Hannan NJ, George AJ, Clyne CD, Ernst M, Allen $\mathrm{AM}$ and Chand $\mathrm{AL}$ : The angiotensin receptor blocker, Iosartan, inhibits mammary tumor development and progression to invasive carcinoma. Oncotarget 8: 18640-18656, 2017.

16 Mendivil AA, Rettenmaier MA, Abaid LN, Brown JV, 3rd, Mori $\mathrm{KM}$ and Goldstein $\mathrm{BH}$ : The impact of total parenteral nutrition on postoperative recovery in patients treated for advanced stage ovarian cancer. Arch Gynecol Obstet 295: 439-444, 2017.

17 Aapro M, Beguin Y, Bokemeyer C, Dicato M, Gascon P, Glaspy J, Hofmann A, Link H, Littlewood T, Ludwig H, Osterborg A, Pronzato P, Santini V, Schrijvers D, Stauder R, Jordan K, Herrstedt $\mathbf{J}$ and Committee EG: Management of anaemia and iron deficiency in patients with cancer: Ann Oncol, 2018. doi: 10.1093/annonc/mdx758 [Epub ahead of print]

18 National Comprehensive Cancer Network: Cancer-and Chemotherapy-induced Anemia (Version 2.2018). Available at https://www.nccn.org/professionals/physician_gls/pdf/anemia.pdf

19 Vergote I, Banerjee S, Gerdes AM, van Asperen C, Marth C, Vaz F, Ray-Coquard I, Stoppa-Lyonnet D, Gonzalez-Martin A, Sehouli $\mathrm{J}$ and Colombo N: Current perspectives on recommendations for BRCA genetic testing in ovarian cancer patients. Eur J Cancer 69: 127-134, 2016. 